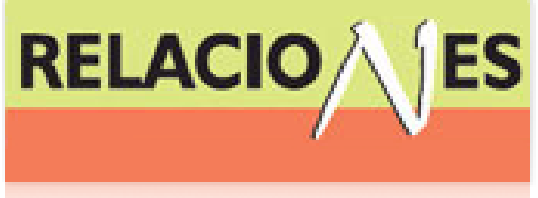

Relaciones. Estudios de historia y sociedad ISSN: 0185-3929

relacion@colmich.edu.mx

El Colegio de Michoacán, A.C

México

Weigand, Phil C.

Para poner en contexto el estudio de Catherine Merridale, Ivan's War: Life and Death in the Red Army, 1939-1945

Relaciones. Estudios de historia y sociedad, vol. XXXII, núm. 126, 2011, pp. 205-219

El Colegio de Michoacán, A.C

Zamora, México

Disponible en: http://www.redalyc.org/articulo.oa?id=13718501008

Cómo citar el artículo

- Número completo

- Más información del artículo

Página de la revista en redalyc.org

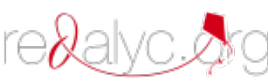

Sistema de Información Científica

Red de Revistas Científicas de América Latina, el Caribe, España y Portugal Proyecto académico sin fines de lucro, desarrollado bajo la iniciativa de acceso abierto 


\title{
Para poner en contexto el estudio de Catherine Merridale, Ivan's War: Life and Death in the Red Army, 1939-1945
}

\author{
Phil C. Weigand* \\ EL COLEGIO DE MICHOACÁN
}

En la Segunda Guerra Mundial, las tierras eslavas de Polonia, Bielorrusia, Ucrania y Rusia fueron el frente europeo más importante y más peleado. Las atrocidades cometidas por el ejercito nazi provocaron una reacción de patriotismo extremo en la URSS y entre los soldados del Ejército Rojo. Con entrevistas a los veteranos de guerra y a sus familias, estudios de documentos ineditos, literatura y cine, Merridale presenta una perspectiva diferente del caracter de la guerra, se concentra en la visión de los soldados participantes en el conflicto. Su estudio representa una mirada desde abajo, el punto de vista casi olvidado por la propaganda oficial. El estudio de Merridale es una etnografía histórica. Combina su estudio con las pocas autobiografías de los soldados. Nos ofrece, por vez primera, una vision realista de los participantes en el Ejército Rojo.

(Segunda Guerra Mundial, Ejército Rojo, URSS/Rusia, patriotismo, nazis)

$\mathrm{V}$

ersiones presenciales de la experiencia de combate durante la Segunda Guerra Mundial escritas por soldados pertenecientes a los Aliados (Estados Unidos, Inglaterra y Francia) e, incluso, por alemanes, son bastante comunes; los recuentos realistas y no censurados, elaborados por participantes del llamado Ejército Rojo (Red Army) de la Unión Soviética, son muy escasos; es decir, de los "ivanes", como se conocieron en esa época a los fusileros y operadores de tanques de esa enorme organización. Recientemente, han aparecido numerosas biografías de los líderes de la URSS,

*Wisarika@aol.com 
especialmente Stalin. Entre las mejores obras sobre Stalin están las de Service (2004), Radzinsky (1996) y Montefiore (2004), cada una presenta una perspectiva distinta y aprovecha, en diferente medida, los archivos que están disponibles desde el colapso de la URSS. Hay también biografías y autobiografías de varios otros participantes importantes; por ejemplo: Saphr (1993) y Chaney (1971; en español, 1975) sobre quien fue, sin duda alguna, el más grande general de la Segunda Guerra Mundial -Zhukov-, así como la versión del propio Zhukov sobre su generalato (editada por Salisbury 2002); así como Taubman (2003) sobre Khrushchev. Narrativas sobre la guerra rusoalemana (la Gran Guerra Patriótica, o el Frente Occidental, como se conoce todavía en Rusia; o el Frente Oriental, como se llama aún en el Occidente debido a la perspectiva alemana), se han multiplicado, casi geométricamente, desde que se abrieron los archivos al escrutinio de estudiosos contemporáneos. También ha sido provechoso el acceso reciente a dichos archivos para ampliar el panorama sobre la respuesta de los civiles soviéticos a la invasión alemana; algunos ejemplos serían los artículos en la colección editada por Thurston y Bonwetsch (2000). Además, algunos novelistas han contribuido. En este sentido, las dos obras de Vasili Grossman, verdaderamente grandiosas, son los mejores ejemplos, su Life y Fate (Vida y destino 2010) y Everything Flows (Todo fluye 2009) son considerados, atinadamente, como clásicos de la literatura rusa del siglo xx, además de su valor etnográfico porque retratan muchos aspectos adustos de la guerra y sus secuelas.

Un excelente ejemplo de un panorama del conflicto germanoruso es la edición revisada del estudio de Seaton (1991), pero existen también análisis desde la perspectiva de la URSS, entre los cuales el estudio monumental de Glantz (2005) es un excelente ejemplo (véanse asimismo: Overy 1997, Gottfried 2003). Algunas de estas obras enfatizan ciertos aspectos temporales del conflicto, como la narrativa de Pleshakov (2005) de los primeros diez días después de iniciada la Operación Barbarossa en junio de 1943; la derrota que sufriera Zhukov al fracasar la Operación Mars en 1942 (Glantz 1999); la batalla de Berlín (Tissier 2008); la campaña alemana contra los partisanos y civiles soviéticos (Shepherd 2004); y la derrota del Army Group Centre de Alemania en junio de 1944 (Adair 
1996). Otras analizan batallas o sitios específicos, como el estudio clásico de Salisbury (1988) de la batalla de Leningrado de 900 días, la campańa que condujo al desastre que sufrieron los alemanes en Stalingrado (Hayward 1998, Beevor 1998, Erickson 1999a; y, desde la perspectiva alemana: Wieder y Graf von Einsiedel 1995), las repercusiones directas de la derrota alemana en Stalingrado (Glantz 2009), la gran batalla de tanques cerca de Kursk (Glantz y House 1999), las campańas Dnepr (Fugate y Dvoretsky 1997), la inacción del Ejército Rojo durante el levantamiento en Varsovia en 1944 (Davies 2003), la invasión de Prusia por el Ejército Rojo (Buttar 2010), y la campaña para tomar Berlín (Erickson 1999b, Beevor 2002, Tissier 2008). Aparte, hay visiones generales nuevas y bien planteadas del contexto político de la guerra y de sus secuelas inmediatas para la URSS (Smyser 1999, Judt 2005, Dallas 2005). Estos títulos son sólo sugerencias para lecturas adicionales y un muestreo simple de los muchos estudios disponibles.

Pero encontramos una perspectiva totalmente diferente en el trabajo de Catherine Merridale, titulado Ivan's War: Life and Death in the Red Army, 1939-1945. Publicado por Metropolitan Books en 2006, este estudio fue aclamado casi inmediatamente, y muy merecidamente, tanto por historiadores como por el público interesado. La edición en español apareció poco después: La guerra de los ivanes: el Ejercito Rojo, 1939-1945 (Editorial Debate, Madrid, 2007). El ambicioso trabajo de Merridale logra presentar un acercamiento fresco, distinto a las biografías de los famosos y la de las batallas y campañas en el frente oriental. Así, su investigación es fundamentalmente diferente a la mayoría de las obras mencionadas arriba, al ser la primera que se enfoca directamente en los soldados del Ejército Rojo, al colocarlos en el centro de su narrativa.

El conflicto alemán-ruso durante la Segunda Guerra Mundial tuvo un largo periodo de incubación que inició con vagas inconformidades tras la invasión napoleónica de Rusia, en que los alemanes participaron en ambos lados (cf. Lieven 2010). Así, estos últimos empezaron a formalizar actitudes - primero culturales y, luego, de superioridad racial- respecto de los eslavos en general y los polacos, rusos y judíos en particular. Para fines del siglo xIX y principios del 
$\mathrm{xx}$, esas actitudes habían evolucionado hasta conformar un eidos organizado con matices explícitamente racistas. En poco tiempo, esta ideología se relacionó con justificaciones imperialistas claras en la Europa oriental; es decir, el infame programa lebensraum comúnmente asociado con Hitler y los nazis, pero que en realidad tuvo un trasfondo histórico más hondo. Con el triunfo alemán sobre Rusia en la Primera Guerra Mundial, formalizado con el Tratado BrestLitovsk firmado con los bolcheviques, la conquista de los estados bálticos y Ucrania, así como el dominio político y económico sobre Polonia y Rumania, quedaron concretados (Fischer 1967, Hillgruber 1981, Weigand en prensa; cf. Stone 1975, Gatrell 2005). Pero el posterior Tratado de Versalles, que negó esas ganancias, fue para el ejército y los políticos alemanes una amarga desilusión. No obstante, la semilla imperialista ya estaba plantada, y conduciría, sólo veinte años después, a una renovada justificación de expansión hacia el este. Muchos alemanes, quizá la mayoría, compartían la idea de que habían ganado ese imperio oriental por justicia, y que les había sido arrancado de manera injusta. El imperativo de recuperar esas ganancias imperiales llegó a ser parte crucial del programa bélico de Hitler; según él, para el supuesto bien mayor de Alemania y de la llamada raza aria (Weigand en prensa, Smith 1986, Liulevicius 2009). El aspecto racista de la invasión alemana de Europa oriental fue directamente responsable de la radicalización de su concepto de "guerra total", barbarie que culminó con el exterminio masivo de gente supuestamente bolchevique y judía, en particular, y un espantoso porcentaje de la población civil eslava en general. Se estima que entre veinte y veinticinco millones de europeos orientales fueron matados por el programa imperialista alemán y su justificación en el lebensraum. De los aproximadamente cinco millones de prisioneros de guerra del Ejército Rojo tomados por los alemanes, sólo alrededor de 30 por ciento sobrevivió a su experiencia en los campos de muerte y los trabajos forzados, que los nazis empezaron a organizar inmediatamente después de iniciar la campaña Barbarossa en Rusia. Ante este escenario de radicalización y barbarismo amparado oficialmente y dirigido contra la población civil, que incluyó el maltrato extremo de los soldados que cayeron prisioneros, el Ejército Rojo 
y la población rusa y soviética no tuvo más remedio que responder.

El proyecto de Merridale empezó como un intento organizado de representar la vida y las experiencias de los fusileros y operadores de tanques; figuras anónimas por mucho tiempo y mayormente olvidadas o tratadas sólo superficialmente en la fuerte campaña propagandística posguerra encaminada a justificar cada aspecto del conflicto, incluidos los evidentes fracasos de los líderes en casi todos los niveles. Los métodos empleados por Merridale fueron entrevistas directas (habla fluidamente el ruso) con sobrevivientes de la guerra y sus familiares, a veces en grupos, pero mayormente en forma individual. Combina las entrevistas con el análisis de las cartas de los soldados, los vastos pero inéditos archivos del servicio secreto y del Ejército Rojo, y versiones publicadas en ruso sin traducción, incluidos periódicos y revistas. Películas, canciones y poesía también son consideradas. Son pocas las narrativas publicadas acerca de soldados o civiles. La extremadamente fascinante versión de Braithwaite (2006) sobre el ambiente civil y político de Moscú en 1941, tras el inicio de la invasión alemana, junto con las biografías de un comandante de tanque por Bessonov (2003); del comandante de una brigada de tanques que llegó al rango de general por Loza (1998); de un artillero antitanques por Moniushko (2005); y de un fusilero por Kravchenko-Berezhnoy (2007), son algunas excepciones. Las biografías escritas por Bessonov, Loza, Moniushko y Kravchenko complementan el estudio de Merridale al ofrecer detalles íntimos de vidas específicas dentro del Ejército Rojo, con experiencias también puntuales de sus confrontaciones con los alemanes. Leídas en su conjunto, estas obras forman el corpus de nuestro actual entendimiento de los ivanes del Ejército Rojo.

En un contexto distinto, con la presentación en 2001 de la película de Paramount Pictures, Enemy at the Gates (Enemigo a la puer$t a$, dirigida por Jean-Jacques Annaud y la direccción de fotografía de Robert Fraise), contamos con una producción comercial que ofrece un retrato dramático del sitio de Stalingrado desde la perspectiva del Ejército Rojo. Los primeros veinte minutos de esta película -antes de convertirse en sólo otra historia hollywoodense- son muy realistas, escenificados de manera aterradora. De las películas comercia- 
les, ésta probablemente da a la cultura popular el retrato más vívido de la vida y muerte de un fusilero del Ejército Rojo. La integración que logra Merridale de archivos e entrevistas, junto con las autobiografías mencionadas arriba, es probablemente lo más cerca que podemos llegar hoy a un entendimiento académico de los ivanes de la Segunda Guerra Mundial. Aunque es historiadora, lo que Merridale realmente presenta es una etnografía histórica de los soldados de dicho ejército. Como Richard Overy (1997) comenta: "Explicaciones materiales de la victoria soviética nunca logran ser muy convincentes". Merridale concuerda y, aunque ciertamente su investigación no ignora el contexto material, se enfoca firmemente en las perspectivas de los soldados, sus incentivos y formación ideológica, y su cultura durante el conflicto. Asimismo, indaga en cómo evolucionó la versión oficial de la guerra -limpiada y desinfectada- una vez terminado el conflicto. Esta última tarea no fue sencilla, ya que de los cinco millones de prisioneros tomados por los alemanes, cerca de 70 por ciento murió de inanición o exceso de trabajo, o simplemente fueron ejecutados. La salud de muchos sobrevivientes quedó quebrantada y un gran número sucumbió a sus lesiones o enfermedades poco después de la guerra. En nada ayudó a su situación el que Stalin tenía sospechas paranoicas de ellos, como si el hecho de haber estado en un campo de muerte o de trabajo alemán realmente constituía una "exposición a la cultura occidental". Muchos más terminaron sus días en los gulags de Siberia o en estaciones de trabajo forzado en otros lugares. Además, del total de 35 millones de hombres y mujeres que fueron movilizados, aproximadamente entre $8 \mathrm{y}$ 9 millones murieron en batalla o por las heridas recibidas. Nadie sabe cuántos civiles fueron asesinados, pero un estimado es de alrededor de 20 millones. Como ya mencioné, es probable que el número total de muertes fuera de 25 millones o más.

Casi inmediatamente después del inicio de Barbarossa, los líderes nazis en el campo se dieron cuenta que su estereotipo oficial del soldado del Ejército Rojo - un salvaje mitad asiático, mitad eslavo (inferior racialmente, inerte y sin motivación) - era erróneo; de hecho, fatalmente equivocado. Era evidente que la fácil victoria que preveían los alemanes (Hitler y el Estado Mayor del ejército habían 
pronosticado que ganarían antes de comenzar el invierno) era efímera, incluso desde los últimos días del otoño. Si bien, el Ejército Rojo sufría de incompetencia en sus niveles más altos (hasta el mismo Stalin), malas comunicaciones y problemas de aprovisionamiento, la situación de los alemanes empeoraba conforme el verano dejaba lugar al otoño. Al padecer severas bajas que incluían muertos y heridos, dificultades de suministro, crecientes patrones de resistencia y sabotaje detrás de sus líneas, discordia entre sus generales, e incompetencia, la campaña alemana se deslizó hacia una empantanada batalla con el Ejército Rojo que distaba mucho del ideal de la blitzkrieg. Rápidamente, la situación se había convertido en una oportunidad que el sistema militar ruso logró mantener, superar y, al final, conseguir el triunfo. La producción industrial de Rusia, combinada con programas de abastecimiento de Estados Unidos e Inglaterra, superó la capacidad alemana desde el inicio de Barbarossa hasta la conquista de Berlín. Por sus recientes experiencias -la Primera Guerra Mundial, la Revolución, la guerra civil, y la invasión extranjera (de 1917 y durante los veinte)- en 1941, el Ejército Rojo debió haber estado mucho mejor preparado, pero no fue así. Merridale muestra que las purgas del ejército en los años treinta, la desastrosa guerra contra Finlandia, y la fantasía de Stalin de derrotar a los nazis con una campańa agresiva, juntas produjeron terribles bajas en las primeras fases de Barbarossa (véanse Getty y Nauman 1999). No obstante, en ese tiempo el pueblo ruso estaba más familiarizado con la guerra que cualquier otro pueblo europeo, incluido el alemán. Si en buena medida se pueden atribuir los orígenes del estado nazi a la derrota de Alemania en la Primera Guerra Mundial, la URSS, en contraste, fue construída directamente por guerras y, en 1941, estaba preparada ideológicamente (pero quizá no estratégica y tácticamente) para pelear una más. Además, toda persona que mostrara su desacuerdo antes, durante o después del conflicto, terminaba detenida por la Cheka/NKvD. Para entonces, deportaciones y ejecuciones no eran sólo comunes, sino formaban parte de la vida diaria de los civiles y militares por igual (véanse Conquest 1990, Applebaum 2003; y la versión "desde adentro" de un desertor del servicio de espionaje: Krivitsky 2000). Junto con los soldados y los 
trabajadores en las fábricas de armamentos, otro elemento clave que permitió al Ejército Rojo prosperar y luego aguantar, repeler y, finalmente, derrotar a la campaña nazi en tan sólo cuatro años fue la combinación de convicción ideológica, temor, opresión, orgullo cívico y, más que nada, un patriotismo nutrido por la repugnancia que sentía el pueblo ruso por el comportamiento alemán.

Las entrevistas con veteranos y civiles de la época están escritas con gran claridad, a veces con presentación dramática, pero siempre en un contexto libre de pretensiones y apologías. Como entrevistadora, Merridale muestra compasión y empatía. En contraste con las historias más formales de la guerra, su investigación es una historia etnográfica de abajo arriba que tiene mucho más en común con las autobiografías ya citadas que con las versiones formales, aunque depende por su presentación e impacto de las herramientas de la historiografía y etnografía formales. Queda claro que a pesar de los años de adoctrinamiento bolchevique, lo que predominó y permitió sacar una victoria de la catástrofe fue el sentido de patriotismo ruso; un patriotismo que salió a lucir después del choque inicial de la derrota de 1941, cuando muchas personas se dieron cuenta que sus familias, ciudades y pueblos estaban amenazados, o ya habían sido destruidos. Para 1942, el primer Ejército Rojo -el que entró en acción en 1941- estaba casi destrozado, porque para entonces la ideología era más importante que el entrenamiento, la buena logística y la estrategia. Junto con los ejércitos de reservistas reclutados en el interior, los sobrevivientes formaron el núcleo de una reorganización lograda rápidamente entre finales de 1941 y principios de 1942. Como ya mencioné, esa destrucción combinada con la ineptitud de los líderes (desde el Kremlin hasta abajo) y carencias de equipamiento dieron al Ejército Rojo poca oportunidad de éxito al inicio de la guerra, aunque una resistencia muy inspirada -pero también poco eficiente- apareció desde el comienzo. Incluso, muchos de los soldados que evitaron ser capturados y quedaron atrás del frente mientras avanzaba, paulatina pero inevitablemente lograron formar celdas de grupos de partidistas que desde un principio acosaban la retaguardia alemana y sus líneas de abasto. El ejército alemán jamás logró controlar todas las áreas atrás del frente. A pesar 
de masacres y la terrible destrucción que sufrieron los civiles, extensos enclaves de resistencia emergieron que, en realidad, fueron inconquistables (Hill 2004, Shepherd 2004).

$\mathrm{Al}$ inicio, la intromisión política desde los más altos niveles menguó tanto el ánimo como el desempeño del Ejército Rojo. Era evidente desde los primeros días que la única estrategia que pudiera ser exitosa consistía en una férrea defensa (la idea de Tukhachevsky, por la cual fue desacreditado), pero se juzgó que esa táctica era incompatible ideológicamente con las fantasías de Stalin. A pesar de tan terrible derrota, el ideal que despertó la simpatía popular fue el de la "madre patria", aunque estaba vestida del lenguaje bolchevique. El segundo Ejército Rojo, simbolizado por Zhukov, sí fue una organización dirigida por generales, aunque su politización y supervisión por oficiales políticos seguía fuerte. Con esa reorganización militar y el impulso de la producción armamentista en fábricas reubicadas fuera del alcance de los nazis, el balance empezó a inclinarse hacia el lado ruso, lenta pero inevitablemente. El apoyo norteamericano y británico que sería tan importante en fases posteriores del conflicto (especialmente cuando enviaron camiones Studebaker) aún no se materializaba. Tras la catástrofe que sufrieron los alemanes en Stalingrado, los ivanes del Ejército Rojo se dieron cuenta que era posible derrotar a los nazis sistemáticamente. Cuando los fusileros se enteraron de las atrocidades que estaban cometiendo los alemanes en escala monumental contra civiles y prisioneros de guerra, la resistencia se consolidó y un hondo deseo de venganza empezó a crecer. En palabras de Merridale:

Durante años, el régimen de Stalin había tratado a la gente como si fuesen ovejas, odiándola y castigando toda iniciativa. Ahora, lentamente, y hasta reaciamente, se encontró presidiendo el surgimiento de un cuerpo de combatientes fuertes y autosuficientes. Este proceso que llevaría meses, se aceleró en 1943; pero, por fin, la ira y odio [al enemigo] se estaban traduciendo en planes claros y fríos (p. 159).

Finalmente, la fantasía del poderío soviético se transformaba y se vio reemplazada por un realismo que generó una verdadera fuerza y resolución. Conforme se disminuía el papel de los oficiales políticos, 
las decisiones militares quedaban cada vez más en manos del ejército y la iniciativa, hasta al nivel del soldado común, emergió en un contexto de profesionalismo y mérito. Esos cambios penetraron en todos los niveles y rangos. De hecho, llegó un momento en que se permitió cierta crítica del sistema (aunque rara vez de Stalin). El orgullo por lo logrado contra el enemigo alemán se disparó, aunque estuvo acompañado de niveles de sufrimiento y privación para los ejércitos de Occidente que fueron de una escala inimaginable, aún difícil de comprender hoy.

El retrato que Merridale presenta de la cultura de los soldados del Ejército Rojo es todo menos superficial. Los entrevistados eran reacios a hablar de las atrocidades que ellos cometieron, limitándose a decir que los alemanes merecían cualquier cosa que recibieron de sus manos. Además, encontró entre los veteranos cierta reticencia a comentar sus relaciones sexuales, consumo de alcohol, saqueos y otras conductas al estar lejos de casa y que no eran acordes con el ideal soviético. En este sentido, sus entrevistas se asemejan a las narrativas autobiográficas ya citadas: de ciertas cosas era mejor no hablar, olvidarlas o descartarlas como poco importantes. Desde luego, esta reticencia estaba relacionada fuertemente con la idealización del conflicto que surgió después de la guerra, y su conversión de los soldados en estereotipos heroicos. De hecho, muchos soldados recibieron honores, beneficios y pensiones que nunca habrían sido posibles en otras condiciones y, por lo mismo, tenían un interés en preservar la versión oficial y superficial de la Segunda Guerra Mundial; ya que sus vidas enteras están entretejidas con el hecho de haber sobrevivido a la guerra (y a la opresión que vino después). Su estatus, sus pensiones y sus relaciones interpersonales dependen de esta versión, aunque con sus entrevistas y, especialmente, las cartas escritas durante el conflicto, Merridale a veces logra romper esta barrera. Hoy, que ya han pasado cerca de tres cuartos de siglo entre los eventos y las entrevistas, lo que emerge más a menudo es una memoria compartida moldeada tanto por la propaganda e idealización como por la experiencia real. Esta tendencia también emerge en las autobiografías, especialmente las que fueron escritas por personas que avanzaron en rango y prestigio después de la guerra. 
El proceso oficial de conmemorar la guerra empezó inmediatamente después de la victoria en Stalingrado. Conforme se desarrollaban los acontecimientos, el nacimiento del mito se intensificó. Hasta las terribles bajas y el inepto liderazgo del primer año de la lucha fueron reinterpretados de manera que el Partido y Stalin (especialmente) relucieran gloriosamente. Stalin, quien nunca perdía una oportunidad de reclamar un eminente papel en el liderazgo militar que realmente no jugó, se convirtió en el dirigente de estas iniciativas, mientras que "Iván" fue convertido en un simple fusilero, obediente, desinteresado, sin género, sobrio, fiel al Partido, mandado siempre por oficiales también abnegados, eficientes, hábiles y, desde luego, el Partido. ¡Urrah!, el temido grito de los fusileros al avanzar, se convirtió en el canto del patriotismo posguerra, aunque, al mismo tiempo, la tercera traición de las metas revolucionarias por Stalin cobraba más fuerza.

El romanticismo que rodea a los fusileros y a las fuerzas armadas del Ejército Rojo, incluida la Marina, no se limitó a la URSS. Recuerdo que cuando era un joven durante la Segunda Guerra Mundial aprendí la valentía de la resistencia rusa, algo que nos enseñaron a admirar. Aún recuerdo parte de una canción que los jóvenes cantábamos en aquel tiempo:

“... join the Russian Navy,

Fight for spuds and gravy.

Fight! Fight! Fight

For Uncle Joe".
“... enrolate en la marina rusa, A pelear por papas y mole. ¡A pelear! ¡A pelear! ¡A pelear! Por tío José".

A pesar de mis años de lecturas intensivas sobre la Segunda Guerra Mundial, el estudio de Merridale, junto con las autobiografías, ha dado mucho más profundidad a los terribles eventos y tragedias que el pueblo ruso sufrió. Como etnografía histórica del Ejército Rojo, no tiene igual. Para lograr un mayor entendimiento de los ivanes del Ejército Rojo, debe ser leído junto con las autobiografías de los fusileros y otro personal armado. Para 1945, la organización militar del Ejército Rojo no tenía igual en el planeta. Cuando sobrevino su paulatina diminución durante los años de la Guerra Fría, 
sólo los veteranos guardaban recuerdos realistas de sus triunfos. Con la reorganización del ejército dentro de la Federación Rusa, sus líderes han insistido en preservar parte del simbolismo del Ejército Rojo. Pero como organización, sigue vivo sólo en los recuerdos, las conmemoraciones, y los estudios académicos de investigadores como Merridale y Glantz.

ReFERENCIAS CITADAS:

Adair, Paul, Hitler's Greatest Defeat: The Collapse of Army Group Centre, June 1944, Londres, Cassell Group, 1996.

Applebaum, Anne, Gulag: A History, Nueva York, Anchor Books, 2003.

BeEvor, Anthony, Stalingrad: The Fateful Siege, 1942-1943, Nueva York, Viking Press, 1997.

—, The Fall of Berlin: 1945, Nueva York, Viking Press, 2002.

Bessonov, Evgeni, Tank Rider: Into the Reich with the Red Army, Londres, Greenhill Books, 2003.

Braithwaite, Rodric, Moscow 1941: A City and its People at War, Nueva York, Alfred Knopf, 2006.

Buttar, Prity, Battleground Prussia: The Assault on Germany's Eastern Front, 1944-1945, Midland House, Osprey Publishing, 2010.

Cheney, Otto, Zhukov, Barcelona, Editorial Euros, 1971.

Conquest, Robert, The Great Terror: A Reassessment, Oxford, Oxford University Press, 1990.

Dallas, Gregor, 1945: The War that Never Ended, New Haven, Yale University Press, 2002.

Davies, Norman, Rising '44: The Battle for Warsaw, Nueva York, Viking Press, 2003.

Erickson, John, The Road to Stalingrad: Stalin's War with Germany, New Haven, Yale University Press, 1999a.

- The Road to Berlin: Stalin's War with Germany, New Haven, Yale University Press, $1999 \mathrm{~b}$.

Fischer, Fritz, Germany's Aims in the First World War, Nueva York, Norton and Company, 1967. 
Fugate, Bryan y Lev Dvoretsky, Thunder on the Dnepr: ZhukovStalin and the Defeat of Hitler's Blitzkrieg, Novato, Presidio Press, 1998.

Gatrell, Peter, Russia's First World War: A Social and Economic History, Edinburgh Gate, Pearson Longman, 2005.

Getty, J. Arch y Oleg V. Naumov, The Road to Terror: Stalin and the Self-destruction of the Bolsheviks, 1932-1939, New Haven, Yale University Press, 1999.

Glantz, David, Zhukov's Greatest Defeat. The Red Army's Epic Disaster in Operación Mars, 1942, Lawrence, University of Kansas Press, 2000.

- Colossus Reborn: The Red Army at War, 1941-1943, Lawrence, University of Kansas Press, 2004.

- After Stalingrad: The Red Army's Winter Offensive 19421943, West Midlands, Helion and Company, 2009.

Glantz, David y Jonathan M. House, The Battle of Kursk, Lawrence, University of Kansas Press, 1999.

GotTfried, Ted, The Great Fatherland War, Twenty-First Century Books, Brookfield, 2003.

Grossman, Vasili, Vida y destino, Barcelona, Random House Mondadori, 2009.

— Everything Flows, Nueva York, New York Review Books Classic, 2009.

HaYward, Joel S.A., Stopped at Stalingrad: The Luftwaffe and Hitler's Defeat in the East, 1942-1943, Lawrence, University of Kansas Press, 1998.

Hill, Alexander, War behind the Eastern Front: The Soviet Partisan Movement in Northwestern Russia, 1941-1944, Londres, Frank Case Publishers, 2004.

Hillgruber, Andreas, Germany and the Two World Wars, Cambridge, Harvard University Press, 1981.

Judt, Tony, Postwar: A History of Europe since 1945, Nueva York, Penguin Press, 2004.

Kravchenko-Berezhnoy, Roman, Victims, Victors: From Nazi Occupation to the Conquest of Germany as Seen by a Red Army Soldier, Bedford, Aberjona Press, 2007. 
Krivitsky, W.G., In Stalin's Secret Service, Nueva York, Enigma Books, 1999.

LozA, Dimitri, Fighting for the Soviet Motherland, Lincoln, University of Nebraska Press, 1998.

Lieven, Dominic, Russia against Napoleon, Nueva York, Viking Press, 2010.

Liulevicius, Vejas, The German Myth of the East. 1800 to the Present, Nueva York, Oxford University Press, 2009.

Merridale, Catherine, Ivan's War: Life and Death in the Red Army, 1939-1945, Nueva York, Metropolitan Books, 2006.

Moniushro, Evgenii, From Leningrad to Hungary, Londres, Frank Case Publishers, 2005.

Montefiore, Simon S., Stalin: The Court of the Red Tzar, Nueva York, Alfred Knopf, 2004.

Overy, Richard, Russia's War: A History of the Soviet Effort, 19411945, Londres, Penguin Books, 1997.

Pleshakov, Constantine, Stalin's Folly: The First Ten Days of World War II on the Eastern front, Nueva York, Houghton Mifflin Co., 2005.

Radzinsky, Edvard, Stalin, Nueva York, Doubleday, 1996.

Salisbury, Harrison E., The 900 Days: The Siege of Leningrad, Nueva York, Da Capo Press, 1985.

Seaton, Albert, The Russo-German War: 1941-45, primera edición, 1971, Novato, Presidio, 1993.

Service, Robert, Stalin: A Biography, Cambridge, Harvard University Press, 2009.

SHEPHERD, Ben, War in the Wild East. The German Army and Soviet Partisans, Cambridge, Harvard University Press, 2004.

Sмітн, Woodruff, The Ideological Origins of Nazi Imperialism, Nueva York, Oxford University Press, 1986.

SMyser, W.R., From Yalta to Berlin: The Cold War Struggle over Germany, Nueva York, St. Martin's Press, 1998.

SpaHr, William J., Zhukov: The Rise and Fall of a Great Captain, Novato, Presidio, 1993.

Stone, Norman, The Eastern Front: 1914-1917, Nueva York, Scribner's, 1995. 
Taubman, William, Khrushchev: The Man and His Era, Nueva York, Norton and Co., 2003.

Thurston, Robert y Bernd Bonwetsch, eds., The People's War: Responses to World War II in the Soviet Union, Urbana, University of Illinois Press, 2000.

Tissier, Tony Le, Marshall Zhukov at the Oder: the Decisive Battle for Berlin, Cirencester Road, Sutton Press, 2008.

Weigand, Phil C., Los antecedentes wilhelminos de la cruzada antieslava y antisemitica de Alemania en la época de nacionalismo socialista, Zamora, El Colegio de Michoacán, en prensa.

Wieder, Jochim y Heinrick Graf von Einsiedel, Stalingrad: $M e-$ mories and Reassessments, Londres, Cassell Publishers, 1993.

Zhukov, Georgi, Marshall Zhukov's Greatest Battles, Nueva York, Cooper Square Press, 2002.

Traducción de Paul C. Kersey Johnson 